TAO, Vol. 15, No. 1, 75-87, March 2004

NOTES AND CORRESPONDENCE

\title{
Absorption Coefficients of Colored Dissolved Organic Matter in the Surface Waters of the East China Sea
}

\author{
Gwo-Ching Gong ${ }^{1, *}$
}

(Manuscript received 22 July 2003, in final form 1 September 2003)

\begin{abstract}
Seasonal and spatial variations in the sea surface absorption coefficients of colored dissolved organic matter in the entire shelf of the East China Sea were studied extensively. The absorption coefficients generally showed a decreasing trend from the inner shelf near the China coast toward the offshore direction in all four seasons. The results indicate that more than $75 \%$ of the shelf waters belong to the Case 2 water category. It was ascertained that the entire absorption spectra in the $U V(\lambda=250 \mathrm{~nm})$ to the Visible $(\lambda=500 \mathrm{~nm})$ range could not be well-described when only one single exponential decay function was employed. Four discontinuity points at wavelengths of around $250,275,325$ and $400 \mathrm{~nm}$ in the log-transformed absorption spectra were noted. Based on the regressive analysis of a total of 137 absorption spectra, the mean slopes of the exponential decay constant at 250, 275, 325 and $400 \mathrm{~nm}$ were $0.018 \pm 0.004,0.025 \pm 0.004$, $0.015 \pm 0.002$ and $0.012 \pm 0.002 \mathrm{~nm}^{-1}$, respectively. In addition, it was found that the values of the absorption coefficients had a high linear correlation with salinity. This suggests that in terms of mixing, the concentrations of colored dissolved organic matter were mostly conservative. The finding of such a relationship provides researchers with the opportunity to obtain remotely obtain the absorption coefficients of colored dissolved organic matter by using the newly-developed Scanning Low-Frequency Microwave Radiometer (SLFMR) technique.
\end{abstract}

(Key words: Absorption coefficient, Colored dissolved organic matter, Case 2 water, East China Sea)

1 Department of Oceanography, National Taiwan Ocean University, Keelung, Taiwan, ROC

Corresponding author address: Prof. Gwo-Ching Gong, Department of Oceanography, National Taiwan Ocean University, Keelung, Taiwan, ROC; Email: gcgong@mail.ntou.edu.tw 


\section{INTRODUCTION}

Satellite ocean-color chlorophyll algorithms (O'Relly et al. 1998; Carder et al. 1999) used today are able to derive quite reasonable chlorophyll concentrations in most of the ocean waters which optically fall into the Case 1 water category in which their optical properties are regulated by phytoplankton and their related particles (Morel and Prieur 1977). Nevertheless, it is also well recognized that such types of global algorithms are flawed when it comes to Case 2 waters in which their optical properties are not just influenced by phytoplankton and its related particles but by other substances, such as the inorganic suspended particles and dissolved colored organic matter. One of the key reasons for the algorithms to fail in this type of water is the interference from the strong absorption of colored dissolved organic matter in the blue band that overlaps phytoplankton chlorophyll absorption. Case 2 waters are primarily in coastal regions and marginal seas, hence being home to $90 \%$ of the world's fish catch and $14 \%$ of global ocean primary production (Parslow et al. 2000; Pernetta and Milliman 1995). Therefore, from the perspective of coastal management and continental shelf carbon pump studies, it is crucial to have an accurate Case 2 water ocean-color chlorophyll algorithm. Unfortunately, such an algorithm that may be applied globally might not be easily attained in that the constituents that affect colors in the waters vary tremendously both regionally and even temporally (IOCCG 2000). For these reasons, a clear understanding of the colored dissolved organic matter in the waters of interest is necessary before a regional Case 2 water algorithm can be developed.

The spectral shapes of absorption coefficient spectra $a_{c d o m}(\lambda)$ in the visible range have been reported by various researchers (e.g., Bricaud et al. 1981; Roesler et al. 1989) who have shown that it should follow an exponential decay function. Therefore, the spectral information with respect to $a_{c d o m}(\lambda)$ can only be obtained by measuring $a_{c d o m}(\lambda)$ at a specific wavelength (e.g., $400 \mathrm{~nm}$ ) and with a known mean slope, $S$, of the exponential decay constant. However, $a_{c d o m}(\lambda)$ in the UV band has become more important, especially for studying Case 2 waters and for identifying red tide blooms (Kahru and Mitchell 1998). The $a_{c d o m}(\lambda)$ in the UV band can also provide a better signal-to-noise ratio than that in the Visible band when attempting to identify colored dissolved organic matter concentrations (Kahru and Mitchell 2001). Hence, it is well worth studying $a_{c d o m}(\lambda)$, as it extends to the UV range.

In the present paper, seasonal variations and the spatial distributions of colored dissolved organic matter in the entire shelf of the East China Sea were investigated. Totally 137 absorption spectra of colored dissolved organic matter collected on four seasonal cruises were fully analyzed. The mean slopes at some specific wavelengths of the exponential decay function that were used to describe the absorption spectra of colored dissolved organic matter were determined. The results provide information that allows for a better understanding of the applicability of present day satellite-derived chlorophyll concentrations (e.g., SeaWiFS) and presents further uses for a regional ocean color chlorophyll algorithm for the East China Sea. 


\section{MATERIALS AND METHODS}

The data presented here were collected from four seasonal cruises on board the $R V$ Ocean Researcher I between December 1997 and November1998. About 34-35 stations, extending from the China coast to the offshore region where the Kuroshio flows, were occupied on each cruise (see Fig. 2 for station locations). Surface seawater samples (normally 2 or $5 \mathrm{~m}$ below sea surface) were collected with a Rosette sampler with 20 L Go-Flo bottles (General Oceanic Inc., USA) mounted on a CTD assembly for the purpose of analyzing salinity and colored dissolved organic matter. Samples for salinity measurements were placed into $120 \mathrm{~mL}$ glass bottles (QorPak) and kept in darkness. In the next stage, salinity was manually determined with an Autosal salinometer (8400B, Guildline Inc.), which was calibrated with standard seawater (IAPSO) before determination. Meanwhile, samples for colored dissolved organic matter analysis were filtered immediately after collection through Neuclepore PC filters of $0.2 \mu \mathrm{m}$ pore size. The filtrates were stored in blown $120 \mathrm{~mL}$ glass bottles (QorPak) kept in the dark at $-20^{\circ} \mathrm{C}$ for $1-2$ weeks before analysis. The absorbance spectra, $\mathrm{A}(\lambda)$, were measured in a $10 \mathrm{~cm}$ quartz cuvette at wavelengths from 250 to $800 \mathrm{~nm}$ using a double-beam spectrometer (Perkin Elmer Lambda 900 UV/VIS/NIR). Purified Milli-Q water (Millipore, Synthesis A10) was used for the baseline correction of the spectrometer before analysis. The absorption coefficient spectra of colored dissolved organic matter, $a_{c d o m}(\lambda)$, were calculated as follows:

$$
a_{c d o m}(\lambda)\left(m^{-1}\right)=2.303 * \mathrm{~A}(\lambda) / \mathrm{L},
$$

where $\mathrm{L}$ is the cuvette lightpath length $(\mathrm{L}=0.1 \mathrm{~m}$ in this case). Based on previous studies (e.g., Bricaud et al. 1981; Roesler et al. 1989), $a_{c d o m}(\lambda)$ can be expressed as an exponential decay function as follow:

$$
a_{c d o m}(\lambda)=a_{c d o m}\left(\lambda_{0}\right) \exp \left[-\mathrm{S} *\left(\lambda-\lambda_{0}\right)\right],
$$

where $\lambda_{0}$ and $\mathrm{S}$ are a reference wavelength and a statistically determined slope of the exponential decay function, respectively. In the present study, $\lambda_{0}$ can be $250,275,325$ or $400 \mathrm{~nm}$. $\mathrm{S}$ is calculated from the least-square fit of the above equation from wavelengths in the ranges of $250-275 \mathrm{~nm}, 275-325 \mathrm{~nm}, 325-400 \mathrm{~nm}$ and $400-500 \mathrm{~nm}$ (see the Results section for an explanation as to the choice of intervals).

\section{RESULTS AND DISSCUSSIONS}

Before the data were analyzed, the spectral shapes of $a_{c d o m}(\lambda)$ from wavelengths of 250 to $500 \mathrm{~nm}$ were examined in detail. An example that illustrated the spectral shapes of $a_{c d o m}(\lambda)$ with high, medium and low levels of absorption colored dissolved matter was shown in Fig. 1. It was noted that the underestimation will be encountered if the value of $a_{c d o m}(\lambda)$ in the UV range was extrapolated by using one single exponential function that was usually employed in 


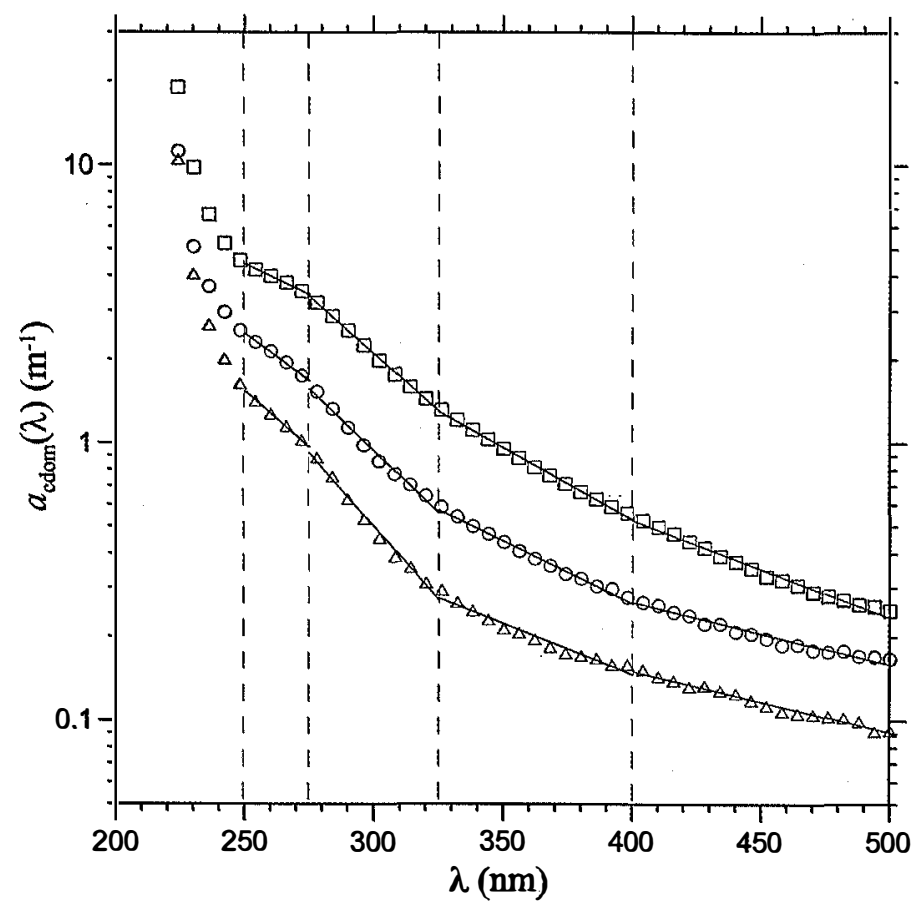

Fig. 1. Example of the log-transformed absorption coefficient spectra of colored dissolved organic matter $\left[a_{c d o m}(\lambda)\right]$ for waters with high $(\square)$, medium $(O)$ and low $(\Delta)$ values. Linear curves in the graph are the regression lines at each interval (see text for explanation).

the visible range (see Fig. 1). In the present study, four discontinuity points in the exponential decay curve at wavelengths of around 250, 275, 325 and $400 \mathrm{~nm}$ were observed. However, the origin of the discontinuity points is still unknown. In fact, the slight discontinuity points at wavelengths around 250, 325 or $350 \mathrm{~nm}$ had previously been found in the report of Bricaud et al. (1981). Consequently, for a regressive analysis to obtain the best $S$ at each interval, the whole $a_{\text {cdom }}(\lambda)$ spectrum was divided into 4 intervals, more specifically in the ranges of $250-275 \mathrm{~nm}, 275-325 \mathrm{~nm}, 325-400 \mathrm{~nm}$ and $400-500 \mathrm{~nm}$.

The values of $a_{\text {cdom }}(\lambda)$ at the wavelengths of $250,275,325$ and $400 \mathrm{~nm}$ for all cruises were found to be respectively within the ranges of 1.022-4.974, 0.507-3.705, 0.058-1.400 and $0.017-0.444 \mathrm{~m}^{-1}$. The values of $\mathrm{S}$ at the same wavelengths were found to be within the ranges of $0.011-0.027,0.018-0.035,0.010-0.023$ and $0.007-0.018 \mathrm{~nm}^{-1}$, respectively. The overall mean values of $S$ at these wavelengths were $0.018 \pm 0.004,0.025 \pm 0.004,0.015 \pm 0.002$ and $0.012 \pm 0.002 \mathrm{~nm}^{-1}$, respectively. Detailed information with regard to $a_{c d o m}(\lambda)$ and its corresponding exponential decay constants at the wavelengths of 250, 275, 325 and $400 \mathrm{~nm}$ for the four cruises are listed in Table 1. As for the mean values of $\mathrm{S}$, besides that at the $250 \mathrm{~nm}$ 
Table 1. Range in the variations on the four cruises of the absorption coefficients of $a_{c d o m}(\lambda)\left(\mathrm{m}^{-1}\right)$ at wavelengths of 250, 275, 325 and $400 \mathrm{~nm}$ and the corresponding slopes, $\mathrm{S}\left(\mathrm{nm}^{-1}\right)$, calculated from the regressive analysis of the absorption spectra. $\mathrm{N}$ is the number of data sets for each cruise.

\begin{tabular}{|c|c|c|c|c|c|c|c|c|c|c|c|c|c|c|}
\hline \multirow[t]{2}{*}{ Chise } & \multirow[t]{2}{*}{ Date } & \multirow[t]{2}{*}{$\mathrm{N}$} & \multirow{2}{*}{$\frac{a_{\text {odorn }}(250)}{\text { Range }}$} & \multicolumn{2}{|c|}{$S(\lambda=250)$} & \multirow{2}{*}{$\frac{a_{\text {odom }}(275)}{\text { Range }}$} & \multicolumn{2}{|c|}{$S(\lambda=275)$} & \multirow{2}{*}{$\frac{a_{\text {odom }}(325)}{\text { Range }}$} & \multicolumn{2}{|c|}{$S(\lambda=325)$} & \multirow{2}{*}{$\begin{array}{c}a_{\text {cdorn }}(400) \\
\text { Range }\end{array}$} & \multicolumn{2}{|c|}{$S(\lambda=400)$} \\
\hline & & & & Range & Mean & & Range & Mean & & Range & Mean & & Range & Mean \\
\hline 511 & $\begin{array}{c}\text { Dec. 19-30, } \\
1997\end{array}$ & 34 & $\begin{array}{c}1.022 \sim ~ \\
3.618\end{array}$ & $\begin{array}{c}0.013 \sim \\
0.026\end{array}$ & $\begin{array}{c}0.019 \\
(0.004)\end{array}$ & $\begin{array}{l}0.507 \sim \\
2.548\end{array}$ & $\begin{array}{c}0.018 \sim \\
0.034\end{array}$ & $\begin{array}{c}0.025 \\
(0.004)\end{array}$ & $\begin{array}{c}0.058 \sim \\
1.020\end{array}$ & $\begin{array}{c}0.012 \sim \\
0.023\end{array}$ & $\begin{array}{c}0.016 \\
(0.003)\end{array}$ & $\begin{array}{c}0.017 \sim \\
0.333\end{array}$ & $\begin{array}{c}0.010 \sim \\
0.016\end{array}$ & $\begin{array}{c}0.013 \\
(0.002)\end{array}$ \\
\hline 515 & $\begin{array}{c}\text { Mar. 16-27, } \\
1998\end{array}$ & 35 & $\begin{array}{l}1.253 \sim \\
3.674\end{array}$ & $\begin{array}{c}0.012 \sim \\
0.027\end{array}$ & $\begin{array}{c}0.018 \\
(0.004)\end{array}$ & $\begin{array}{c}0.684 \sim \\
2.677\end{array}$ & $\begin{array}{c}0.020 \sim \\
0.032\end{array}$ & $\begin{array}{c}0.025 \\
(0.003)\end{array}$ & $\begin{array}{c}0.106 \sim \\
0.937\end{array}$ & $\begin{array}{c}0.011 \sim \\
0.019\end{array}$ & $\begin{array}{c}0.014 \\
(0.002)\end{array}$ & $\begin{array}{c}0.029 \sim \\
0.283\end{array}$ & $\begin{array}{c}0.009 \sim \\
0.016\end{array}$ & $\begin{array}{c}0.012 \\
(0.002)\end{array}$ \\
\hline 521 & $\begin{array}{c}\text { Jum. 28-Jul } \\
7,1998\end{array}$ & 34 & $\begin{array}{l}1.308 \sim ~ \\
4.974\end{array}$ & $\begin{array}{c}0.011 \sim \\
0.027\end{array}$ & $\begin{array}{c}0.017 \\
(0.004)\end{array}$ & $\begin{array}{c}0.646 \sim \\
3.705\end{array}$ & $\begin{array}{l}0.018 \sim \\
0.035\end{array}$ & $\begin{array}{c}0.025 \\
(0.004)\end{array}$ & $\begin{array}{c}0.125 \sim \\
1.400\end{array}$ & $\begin{array}{l}0.013 \\
0.020\end{array}$ & $\begin{array}{l}0.015 \sim \\
(0.002)\end{array}$ & $\begin{array}{c}0.029 \sim \\
0.444\end{array}$ & $\begin{array}{c}0.007 \sim \\
0.016\end{array}$ & $\begin{array}{c}0.012 \\
(0.002)\end{array}$ \\
\hline 532 & $\begin{array}{l}\text { Oct. 21-Nov. } \\
5,1998\end{array}$ & 34 & $\begin{array}{c}1.220 \sim \\
3.880 \\
\end{array}$ & $\begin{array}{c}0.013 \sim \\
0.026 \\
\end{array}$ & $\begin{array}{c}0.018 \\
(0.003) \\
\end{array}$ & $\begin{array}{c}0.618 \sim \\
2.784 \\
\end{array}$ & $\begin{array}{c}0.020 \sim \\
0.032 \\
\end{array}$ & $\begin{array}{c}0.025 \\
(0.003) \\
\end{array}$ & $\begin{array}{c}0.144 \sim \\
1.041 \\
\end{array}$ & $\begin{array}{l}0.010 \\
0.020 \\
\end{array}$ & $\begin{array}{l}0.015 \sim \\
(0.003) \\
\end{array}$ & $\begin{array}{c}0.045 \sim \\
0.303 \\
\end{array}$ & $\begin{array}{c}0.008 \sim \\
0.018 \\
\end{array}$ & $\begin{array}{c}0.013 \\
(0.003) \\
\end{array}$ \\
\hline All & & 137 & $\begin{array}{c}1.022 \sim \\
4.974 \\
\end{array}$ & $\begin{array}{c}0.011 \sim \\
0.027 \\
\end{array}$ & $\begin{array}{c}0.018 \\
(0.004) \\
\end{array}$ & $\begin{array}{c}0.507 \sim \\
3.705 \\
\end{array}$ & $\begin{array}{c}0.018 \sim \\
0.035 \\
\end{array}$ & $\begin{array}{c}0.025 \\
(0.004) \\
\end{array}$ & $\begin{array}{c}0.058 \sim \\
1.400 \\
\end{array}$ & $\begin{array}{c}0.010 \sim \\
0.023 \\
\end{array}$ & $\begin{array}{c}0.015 \\
(0.002) \\
\end{array}$ & $\begin{array}{c}0.017 \sim \\
0.444 \\
\end{array}$ & $\begin{array}{c}0.007 \sim \\
0.018 \\
\end{array}$ & $\begin{array}{c}0.012 \\
(0.002) \\
\end{array}$ \\
\hline
\end{tabular}


wavelength, it is obvious that $S$ decreased from $0.025 \mathrm{~nm}^{-1}\left(\lambda_{0}=275 \mathrm{~nm}\right)$ to $0.012 \mathrm{~nm}^{-1}\left(\lambda_{0}=\right.$ $400 \mathrm{~nm})$. The mean value of $S$ at the wavelength of $400 \mathrm{~nm}$ was only $50 \%$ of that at $275 \mathrm{~nm}$, indicating that underestimations would result if information related to $a_{c d o m}(\lambda)$ at wavelengths shorter than $400 \mathrm{~nm}$ were calculated and extrapolated on the basis of the mean slope, $\mathrm{S}$, at the wavelength of $400 \mathrm{~nm}$. In the present study, the mean value of $S$ at that wavelength $(0.012 \pm$ $0.002 \mathrm{~nm}^{-1}$ ) was substantially lower than the published mean value of $0.016 \pm 0.002 \mathrm{~nm}^{-1}$ (Roesler at al. 1989). Significant variations in the mean values of $S$ on each cruise were not apparent (see Table 1).

As stated, the data presented in this study were collected on four seasonal cruises at various stations extending the entire shelf of the East China Sea, and as a consequence, they also allow us to look at the temporal and spatial distributions of $a_{c d o m}(\lambda)$ in the East China Sea. Figure 2 shows the spatial distributions of $a_{c d o m}(325)$ for the four seasons. The spatial distributions of $a_{c d o m}(\lambda)$ at other wavelengths show similar patterns to those of $a_{c d o m}(325)$, and hence are not presented here. In general, the spatial distributions of $a_{c d o m}(325)$ decrease from the inner shelf near the China coast toward the offshore region for all seasons. It is evident that more highly colored dissolved organic matter in the inner shelf was input from terrestrial rivers along the China coast. The much higher values of $a_{c d o m}(325)$ (see $0.8 \mathrm{~m}^{-1}$ isopleth in Fig. 2) can most likely be attributed to river runoff from the Changjiang (the third largest river in the world) to the north and the Mingjiang to the south (see Fig. 2 for these locations). Lower concentrations of colored dissolved organic matter found in the offshore region were probably due to the flow of the Kuroshio (Gong et al. 1996, 2000).

Aside from this, the seasonal spatial patterns indicate that patches with higher values of $a_{c d o m}(325)$ appeared in different locations. In summer, the patches with the highest $a_{c d o m}(325)$ were distributed on the eastern side of the Changjiang River mouth (Fig. 2c) while in other seasons, the patches with the highest $a_{c d o m}(325)$ were distributed south of the Changjiang River mouth (Figs. 2a, b, d). The differences in these locations could be a result of changes in the prevailing monsoons. To explain, in summer, the input of colored dissolved organic matter from the Changjiang River mouth influenced by the prevailing southwest monsoon most probably led to the eastward spreading of the higher $a_{c d o m}(325)$ values. In other seasons, more highly colored dissolved organic matter was limited to the coast indicated which might indicate a line source from the China coast. It is noted that one other higher $a_{c d o m}(325)$ patch located along the southermmost of China coast west of Taiwan was found both in summer and autumn (Figs. 2c, d). The results indicate that the contributions of colored dissolved organic matter from the Mingjiang to the shelf should not be ignored.

The occupation of less colored dissolved organic matter [see $a_{c d o m}(325)=0.4 \mathrm{~m}^{-1}$ isopleth)] is also indicative of seasonality. The lower values of $a_{c d o m}(325)$ were found to be more extensive on the shelf in winter and autumn than in other seasons. These results might very well correspond to the intrusion of saline oligotrophic Kuroshio waters which begin to intrude onto the shelf during the late autumn (Tang et al. 2000).

This indicates that the seasonal distribution of colored dissolved organic matter might largely be regulated by seasonal fluctuations in the circulation in the East China Sea shelf. Further evidence of the influence of circulation on the distribution of colored dissolved or- 
ganic matter is observed in the spatial distribution of sea surface salinity. Figure 3 shows the distribution of sea surface salinity that corresponds to the four seasonal distributions of $a_{c d o m}(325)$. Noteworthy is that the distribution of sea surface salinity mirrors the distribution of $a_{c d o m}(325)$ which increases from the inner shelf near the China coast in the seaward direction in all seasons. The distribution of the lower salinity water patches are generally identical to that of $a_{c d o m}(325)$ patches of higher value. In summer, the lowest salinity patch (see $\mathrm{S}=32$

(a)

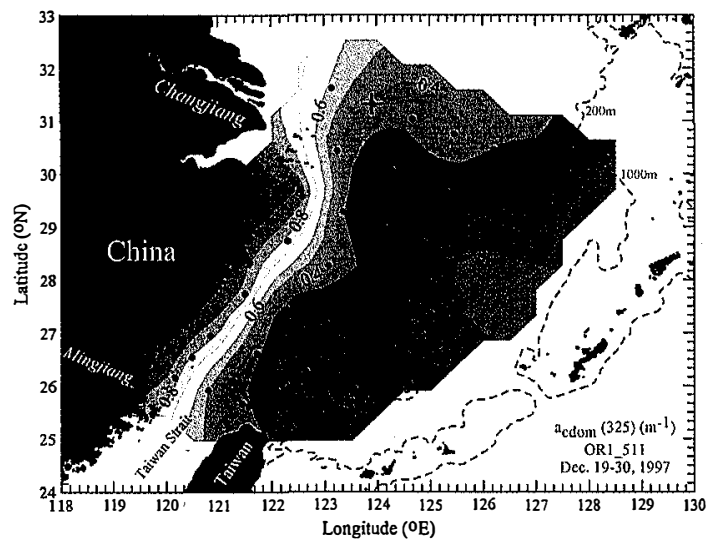

(c)

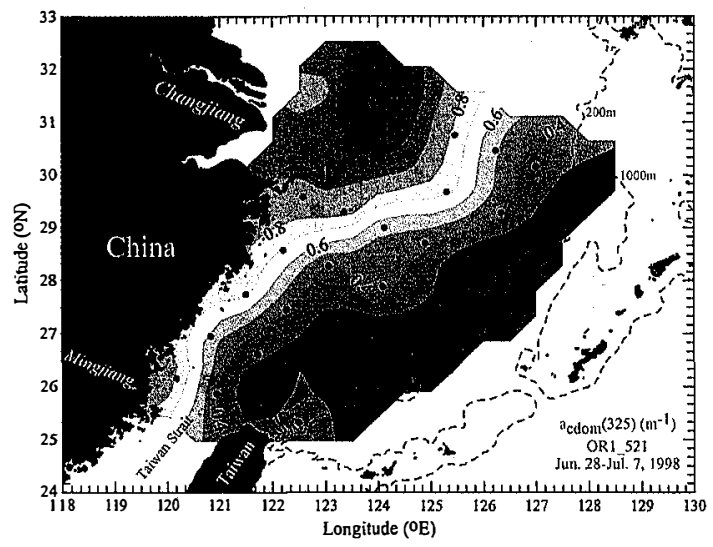

(b)

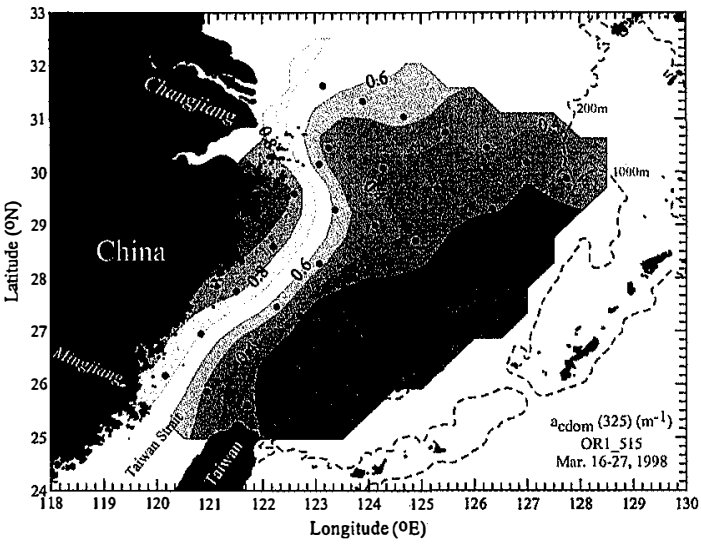

(d)

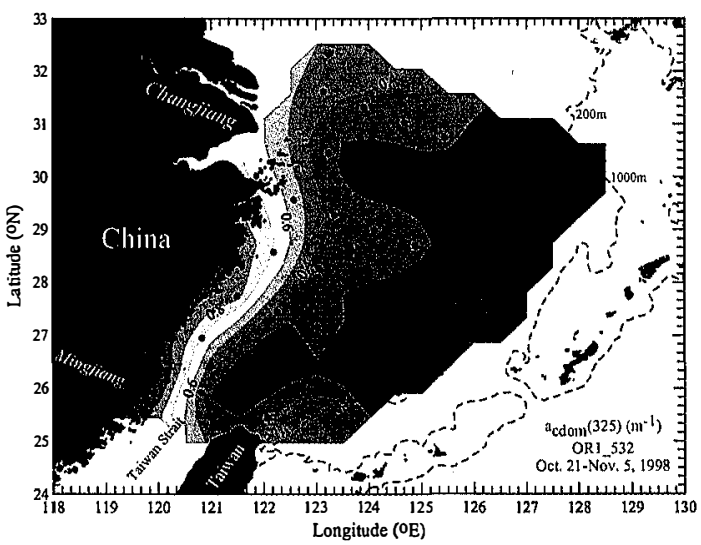

Fig. 2. Spatial distribution of the sea surface absorption coefficients of colored dissolved organic matter at wavelength $325 \mathrm{~nm}\left[a_{c d o m}(325)\right]$ for four seasonal cruises: (a) OR1_511; (b) OR1_515; (c) OR1_521; and (d) OR1_532. Symbols $(+)$ and $(\Delta)$ shown in Fig. 1a are stations that provide direct match-up data between in-situ measurements and SeaWiFSderived chlorophyll $a$ concentrations. 
isohaline) was in the eastward direction off the Changjiang River mouth (Fig. 3c), whereas in other seasons, it was limited to the region south of the Changjiang River mouth near the China coast (Figs. 3a, b, d). Patches of $a_{\text {cdom }}(325)$ with the second highest values (Figs. 2c, d) in summer and autumn also corresponded to patches with lower salinity (Figs. 3c, d). The results again make it obvious that the higher concentrations of colored dissolved organic matter were mostly contributed by river runoff. On the other hand, the seasonal variations with respect to the occupation of water with higher salinity (see $S=34.0$ isohaline) were similar to the distributions of lower values of $a_{c d o m}(325)\left(=0.4 \mathrm{~m}^{-1}\right)$, which illustrates the effects of seasonal fluctuations in the saline Kuroshio waters on the distribution of colored dissolved matter.

In light of the finding of similar seasonal distributions between salinity and $a_{c d o m}(325)$,

(a)

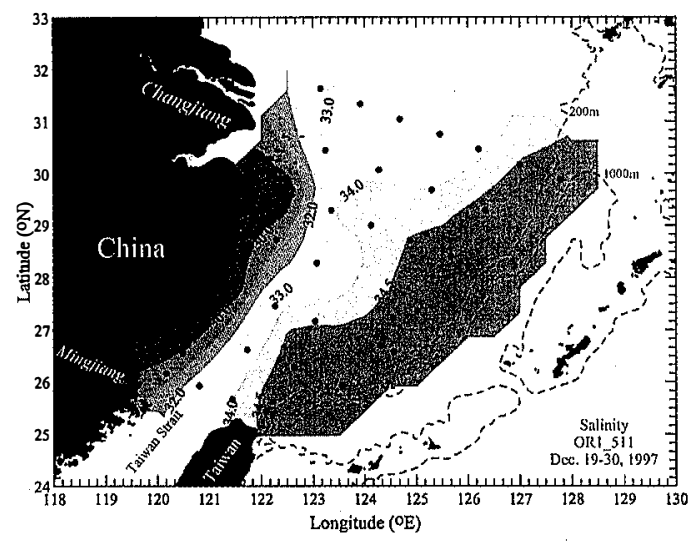

(c)

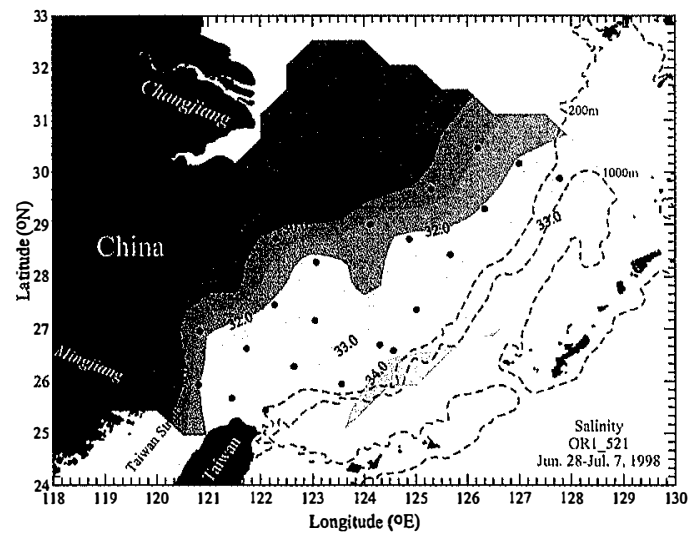

(b)

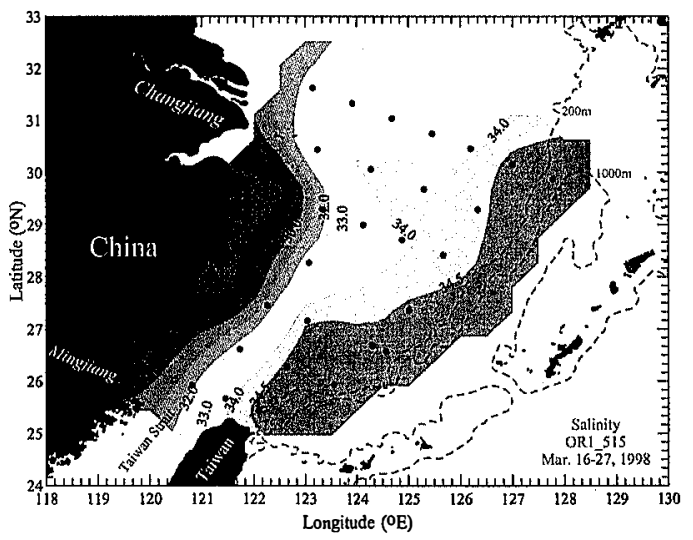

(d)

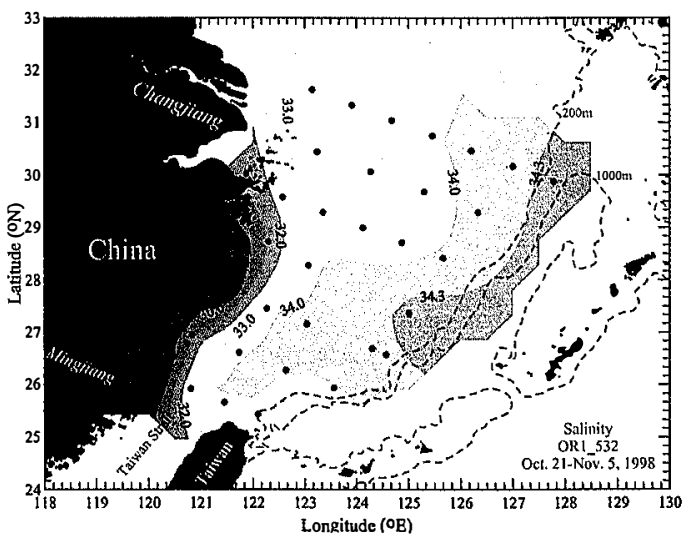

Fig. 3. Spatial distribution of sea surface salinity for the four seasonal cruises: (a) OR1_511; (b) OR1_515; (c) OR1_521; and (d) OR1_532. 
the relationships between them were further examined. It was found that the values of $a_{c d o m}(\lambda)$ at the four selected wavelengths had higher linear correlations with salinity for data collected on all four cruises. Figure 4 presents an example of the relationships between salinity and $a_{c d o m}(325)$. Similar results were found at other wavelengths of $a_{\text {cdom }}(\lambda)$, and hence are not presented here. Detailed results from the linear regressive analysis of the relationships between salinity and $a_{c d o m}(\lambda)$ are shown in Table 2. Regarding the relationships between salinity and $a_{\text {cdom }}(325)$, the linear relationships resembled each other in all seasons but not in summer. Most of the $a_{c d o m}(325)$ data associated with higher salinity $(\mathrm{S}>32)$ had lower values in summer than in other seasons. It was also found that the lower the wavelength chosen, the higher was the linear correlation coefficient obtained (Table 2). The existence of the linear relationships between salinity and $a_{c d o m}(\lambda)$ shows that colored dissolved organic matter in the present study area closely followed conservative mixing.

One of the key conditions that promises that the satellite-derived chlorophyll $a$ concentrations data are reasonably accurate is dependent on the values of $a_{c d o m}(380)$. It is suggested that the value should be less than $0.1 \mathrm{~m}^{-1}$ for SeaWiFS data (Mueller and Austin 1995). Based

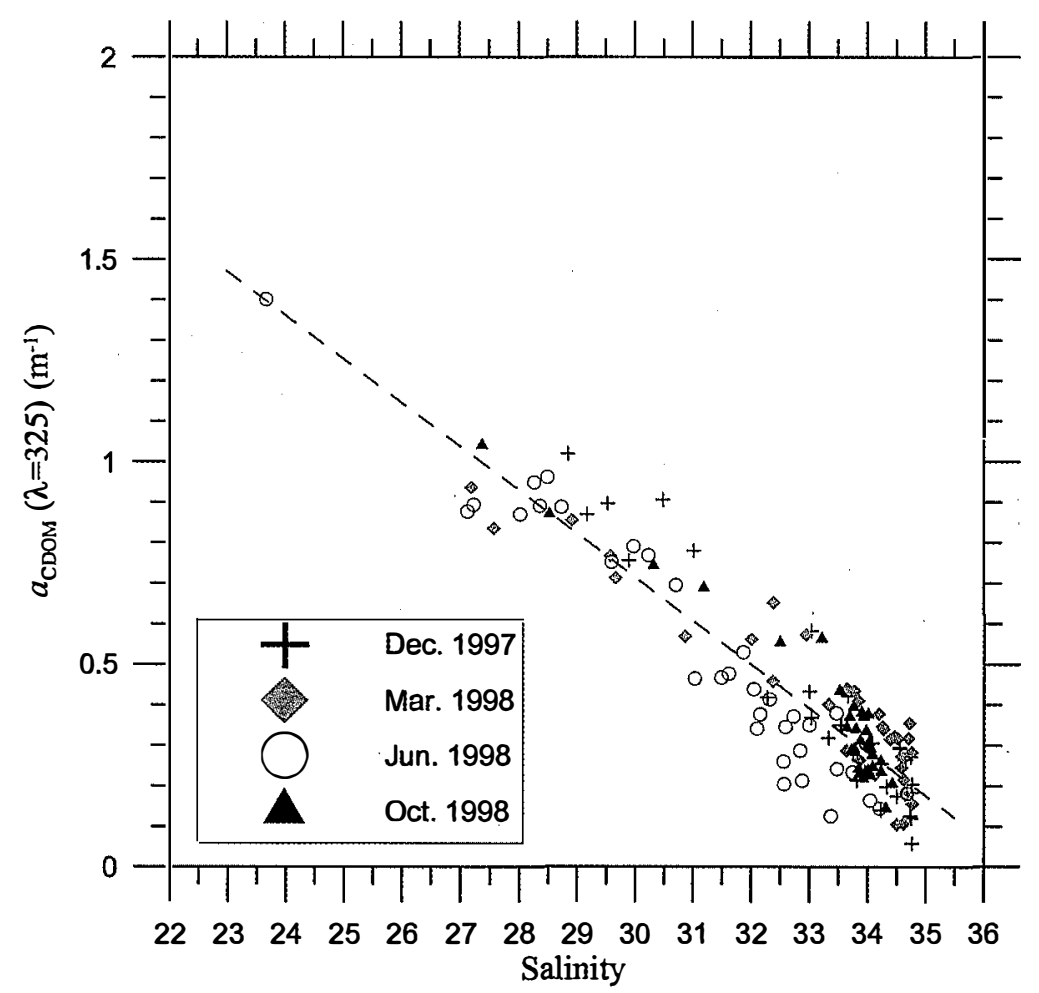

Fig. 4. Relationships between salinity and the absorption coefficients of colored dissolved organic matter at wavelength $325 \mathrm{~nm}\left[a_{c d o m}(325)\right]$. 
Table 2. Results showing the linear relationships between salinity and the absorption coefficients of colored dissolved organic matter at wavelengths of $250,275,325$ and $400 \mathrm{~nm} . \mathrm{R}^{2}$ is the linear correlation coefficient calculated from the least-square fit analysis.

\begin{tabular}{|c|c|c|c|c|c|c|c|c|c|c|c|c|c|c|}
\hline \multirow[t]{2}{*}{ Crise } & \multirow[t]{2}{*}{ Date } & \multirow[t]{2}{*}{$\mathrm{N}$} & \multicolumn{3}{|c|}{$a_{\text {cdom }}(250)=\alpha^{*}$ Salinity $+\beta$} & \multicolumn{3}{|c|}{$a_{\text {cdom }}(275)=\alpha^{*}$ Salinity $+\beta$} & \multicolumn{3}{|c|}{$a_{\text {cdom }}(325)=\alpha *$ Salinity $+\beta$} & \multicolumn{3}{|c|}{$a_{\text {cdom }}(400)=\alpha^{*}$ Salinity $+\beta$} \\
\hline & & & $\alpha$ & $\beta$ & $\mathrm{R}^{2}$ & $\alpha$ & $\beta$ & $\mathrm{R}^{2}$ & $\alpha$ & $\beta$ & $\mathrm{R}^{2}$ & $\alpha$ & $\beta$ & $\mathrm{R}^{2}$ \\
\hline 511 & $\begin{array}{c}\text { Dec. 19-30, } \\
1997\end{array}$ & 34 & -0.368 & 14.102 & 0.90 & -0.290 & 10.837 & 0.89 & -0.138 & 4.963 & 0.91 & -0.048 & 1.735 & 0.91 \\
\hline 515 & $\begin{array}{c}\text { Mar. 16-27, } \\
1998\end{array}$ & 35 & -0.303 & 12.079 & 0.90 & -0.238 & 9.182 & 0.90 & -0.093 & 3.506 & 0.86 & -0.025 & 0.962 & 0.72 \\
\hline 521 & $\begin{array}{c}\text { Jun. 28-Jul } \\
7,1998\end{array}$ & 34 & -0.332 & 12.786 & 0.90 & -0.280 & 10.342 & 0.90 & -0.121 & 4.298 & 0.93 & -0.038 & 1.366 & 0.90 \\
\hline 532 & $\begin{array}{c}\text { Oct. 29-Nov. } \\
5,1998 \\
\end{array}$ & 34 & -0.355 & 13.666 & 0.93 & -0.280 & 10.511 & 0.91 & -0.117 & 4.282 & 0.90 & -0.032 & 1.183 & 0.78 \\
\hline All & & 137 & -0.322 & 12.559 & 0.90 & -0.258 & 9.745 & 0.89 & -0.108 & 3.950 & 0.87 & -0.033 & 1.209 & 0.78 \\
\hline
\end{tabular}


on the seasonal distributions of $a_{c d o m}(\lambda)$ shown in Fig. 2, those with values higher than $0.2 \mathrm{~m}^{-1}$ (equivalent to about $a_{c d o m}(380)=0.1 \mathrm{~m}^{-1}$ ) for the most part occupied more than $75 \%$ of the shelf in the East China Sea. In fact, an overwhelmingly high overestimation of about $474 \%$ in the SeaWiFS-derived chlorophyll $a$ concentration $\left(2.29 \mathrm{mg} \mathrm{m}^{-3}\right)$ at a station located about 200 $\mathrm{km}$ east off the Changjiang River mouth (see the triangle symbol in Fig. 2a) was found during the December 1997 cruise. The direct match-up in-situ measured chlorophyll $a$ value at the same station was only $0.40 \mathrm{mg} \mathrm{m}^{-3}$. Fortunately, a reasonable result for a SeaWiFS-derived chlorophyll $a$ concentration $\left(0.27 \mathrm{mg} \mathrm{m}^{-3}\right)$ at an offshore station (see the cross symbol in Fig. 2a) located in waters with values of $a_{c d o m}(325)$ lower than $0.2 \mathrm{~m}^{-1}$ was obtained. This compares with the in-situ measured chlorophyll $a$ concentration at this station was $0.30 \mathrm{mg} \mathrm{m}^{-3}$. This suggests that the use of today's satellite-derived chlorophyll concentrations, like the SeaWiFS or even the historical CZCS data sets in the East China Sea, should be taken with considerable caution; otherwise, it can result in enormous errors.

\section{CONCLUSIONS}

The seasonal distributions of the sea surface absorption coefficients of colored dissolved organic matter collected on four seasonal cruises between December 1997 and November 1998 in the entire shelf of the East China Sea have been reported here. The absorption spectra of colored dissolved organic matter were not found to be suitably described when only a single exponential decay function extending from the UV to the Visible bands was employed. Four discontinuity points at wavelengths $250,275,325$ and $400 \mathrm{~nm}$ were observed in the present data of the absorption spectra. As a result, four intervals from wavelengths ranging from $250 \mathrm{~nm}$ to $500 \mathrm{~nm}$ were used to obtain a more accurate mean slope of the exponential decay constant for the absorption spectra. The mean slope at the wavelength of $400 \mathrm{~nm}$ was $0.012 \mathrm{~nm}^{-1}$ which is somewhat lower than the averaged values of those previously published $\left(0.016 \mathrm{~nm}^{-1}\right)$. The value of the mean slope was seen to decrease from $0.035 \mathrm{~nm}^{-1}$ at $275 \mathrm{~nm}$ to $0.012 \mathrm{~nm}^{-1}$ at 400 $\mathrm{nm}$, which indicates that any extrapolation using a mean slope of $400 \mathrm{~nm}$ down to the shorter wavelengths should be taken with great caution. Based on the seasonal distributions of the absorption coefficients of the colored dissolved organic matter, it was found that more than $75 \%$ of the waters in the continental shelf of the East China Sea were usually occupied by those optically belonging to Case 2 waters. Direct evidence showed significant overestimations of SeaWiFS-derived chlorophyll $a$ concentrations in the waters. It is strongly suggested that the present satellite-derived chlorophyll $a$ data, like SeaWiFS or historical CZCS data set sets, might not be accurate for these waters.

In addition, higher linear correlations between salinity and the values of the absorption coefficients of colored dissolved organic matter at some specific wavelengths were found, indicating that the behavior of colored dissolved organic matter in the study area mostly followed conservative mixing. Finally, the finding of the linear relationship further provides us with an exciting, new technique with great potential by which to obtain remotely information pertaining to the absorption coefficients of colored organic matter from the Scanning Low-Frequency Microwave Radiometer (SLFMR) (Miller 2000). 
Acknowledgements Special thanks are extended to Mssrs. Y. H. Wen, M. H. Liang and G. J. Liu for their assistance with the sampling and sample analyses during the cruises. Personal communications with Drs. Mitchell, G. and M. Kahru regarding the importance and application of colored dissolved organic matter are also appreciated. The help from the SeaWiFS Project (at the NASA Goddard Space Flight Center) for the direct match-ups of the in-situ measurements and SeaWiFS-derived chlorophyll $a$ concentrations is acknowledged. Gratitude is also extended to W. D. Lucas who helped to improve the use of English in the manuscript. The constructive comments and suggestions by Dr. G. T. F. Wong and one anonymous reviewer were appreciated. This research was supported by the National Science Council, R.O.C., under grants NSC91-2611-M-019-018-OP3 and NSC92-2611-M-019-013.

\section{REFERENCES}

Bricaud, A., A. Morel, and L. Prieur, 1981: Absorption by dissolved organic matter of the sea (yellow substance) in the UV and visible domains. Limnol. Oceanog., 26, 43-53.

Carder, K. L., F. R. Chen, Z. P. Lee, and S. K. Hawes, 1999: Semianalytic moderate-Resolution Imaging Spectrometer algorithm for chlorophyll $a$ and absorption with bio-optical domains based on nitrate-depletion temperatures. J. Geophys. Res., 104, 5403-5421.

Gong, G. C., Y. L. Chen, and K. K. Liu, 1996: Chemical hydrography and Chl $a$ distribution in the East China Sea in summer: Implications in nutrient dynamics. Continental Shelf Res., 16, 1561-1590.

Gong, G. C., F. K. Shiah, K. K. Liu, Y. H. Wen, and M. H. Liang, 2000: Spatial and temporal variations of chlorophyll $a$, primary productivity and chemical hydrography in the southern East China Sea. Continental Shelf Res., 20, 411-436.

IOCCG, 2000: Remote sensing of ocean colour in coastal, and other optically-complex waters. Sathyendranath, S. (ed.), Reports of the International Ocean-Colour Coordinating Group, No. 3, IOCCG, Dartmouth, Canada, 140pp.

Kahru, M., and B. G. Mitchell, 1998: Spectral reflectance and absorption of a massive red tide off southern California. J. Geophys. Res., 103, 21601-21609.

Kahru, M., and B. G. Mitchell, 2001: Seasonal and nonseasonal variability of satellite-derived chlorophyll and colored dissolved organic matter concentrations in the California Current. J. Geophys. Res., 106, 2517-2529.

Morel, A., and L. Prieur, 1977: Analysis of variations in ocean color. Limnology and Oceanography, 22, 709-722.

Miller, J. L., 2000: Airborne remote sensing of salinity. Backscatter, 11, 24-27.

Mueller, J. L., and R. W. Austin, 1995: Ocean optics protocols for SeaWiFS validation, Revision 1, NASA Technical Memorandum, 104566, Vol. 25.

O’Reilly, J. E., S. Maritorena, B. G. Mitchell, D. A. Siegel, K. L. Carder, S. A. Garver, M. Kahru, and C. McClain, 1998: Ocean color chlorophyll algorithms for SeaWiFS. J. Geophys. Res., 103, 24937-24953.

Parslow, J. S., H. Hoepffner, R. Doerffer, J. W. Campbell, P. Schlittenhardt, and S. Sathyendranath, 2000: Case 2 Ocean-colour application, In reports of the International 
Ocean-Colour Coordinating Group, No. 3, IOCCG, Dartmouth, Canada, 140pp.

Pernetta, J. C., and J. D. Milliman, 1995: Land-Ocean interaction in the coastal zone implementation plan, IGBP Report No. 33, Stockholm, 215pp.

Roesler, C. S., M. J. Perry, and K. L. Carder, 1989: Modeling in situ phytoplankton absorption from total absorption spectra in productive inland marine waters. Limnol. Oceanog., 34, 1510-1523.

Tang, T. Y., J. H. Tai, and Y. J. Yang, 2000: The flow pattern north of Taiwan and the migration of the Kuroshio. Continental Shelf Res., 20, 349-371. 